\title{
Reusability and Learning Objects: Problems and a Proposed Solution
}

\author{
Namdar Mogharreban and Dave Guggenheim \\ Southern IIlinois University, Carbondale, IL, USA
}

namdar@cs.siu.edu; dguggen@siu.edu

\begin{abstract}
Learning objects have long promised dramatic savings of time and money in course and curricula development, but they have failed to deliver the return on investment that seems a natural extension of their existence - reusability. Because a single hour of online instruction can take up to 300 hours to develop (Kapp 2003), reusability is the core value message offered by learning object promoters, from the earliest days to the present. Yet, after 12 years of successive evolution, learning objects are still primarily a collection of stand-alone modules that rarely interconnect out side of strictly controlled regimes, such as those imposed by corporate and military training guidelines. Among the contributing factors to this impediment are definition of learning object, size of a learning object and aesthetics of a learning object.

In response to this shortcoming, we propose to introduce a new entity - the learning pod. Engineered for reusability, the learning pod incorporates several modules that bring current technology to create an experientially seamless interconnection between disparate learning objects.

These modules communicate with one another to build a consistent unit of instruction that uses several learning objects depending on the requirements. Several technologies including semantic web, XSL/XML and CSS are utilized to achieve presentation cohesiveness.
\end{abstract}

Key words: Learning Object, Reusability, Learning Style, Learning Pod, XSL, XML, XHT ML 